\title{
Variations in the retention of taste aversions: Evidence for retrieval competition
}

\author{
W. ROBERT BATSELL, JR., and MICHAEL R. BEST \\ Southern Methodist University, Dallas, Texas
}

\begin{abstract}
In six experiments, we examined taste and compound taste/taste aversions at different retention intervals. In Experiment 1, saccharin aversions were significantly weaker 1 day after conditioning than 21 days after conditioning. This effect was determined not to be caused by the aftereffects of illness or differential hydration. With the use of a saccharin/denatonium compound, Experiment 2 demonstrated overshadowing of a denatonium aversion at 21- and 1-day retention intervals, Experiment 4 showed a potentiated saccharin aversion only at the 21 -day retention interval, and both Experiments 2 and 4 revealed that the aversion of the taste-only controls was stronger at the later retention interval. Experiments 3 and 5 demonstrated that the differences at the two retention intervals were not caused by unconditioned changes in taste preference. Finally, Experiment 6 showed that extinction of the conditioning environment prior to testing results in stronger saccharin aversions than occur in nonextinguished controls. Collectively, these experiments suggest that testing within a 24-h period after conditioning will result in significantly weaker taste aversions. Also, these results support a retrieval-competition explanation that may account for the weakened aversions at the 1-day testing interval of both groups conditioned to single elements and those conditioned to compounds.
\end{abstract}

Conditioned taste aversions are noted for their strength and can often be reliably established with one pairing of a flavor with toxicosis. Paradoxically, however, if flavor aversions are tested within $24 \mathrm{~h}$ of conditioning, they can appear weaker than if they are tested several days after conditioning. Biederman, Milgram, Heighington, Stockman, and O'Neill (1974) observed weaker saccharin aversions 1 day after conditioning than were observed either 2 or 14 days after conditioning. Similarly, Batsell and M. R. Best (1990) noted weaker saccharin aversions 1 day after conditioning than occurred 3,5, or 10 days after conditioning. Of particular interest in the latter experiment was the nonmonotonic retention function of aversive conditioning. Animals tested 1 day after conditioning drank approximately $16 \mathrm{ml}$ of saccharin, whereas those tested at the 3-, 5-, and 10-day intervals drank between 8 and $10 \mathrm{ml}$. This indicates that aversions to saccharin were not becoming stronger with time; rather, they were somehow obscured at the 1-day testing interval.

The finding that flavor-aversion conditioning appears stronger at longer rather than shorter retention intervals is also relevant to demonstrations of flavor overshadowing. Kraemer, Lariviere, and Spear (1988) and J. S. Miller, Jagielo, and Spear (1990, Experiment 1) paired

This research was supported by NSF Grant BNS-8809508 and by the Federal Aviation Administration. The authors would like to thank the following individuals for their assistance in the completion of this project: Andrew K. Block, Jeannine Georgiades, J. Chris Graves, Allen Hornell, Howard Hurd, Craig Senglin, Theresa Smith, and David Striegel. We would also like to thank Atomergic Chemetals Corporation, 91 Carolyn Boulevard, Farmingdale, NY 11735-1527 for supplying the denatonium saccharide. Address correspondence to Robert Batsell, Department of Psychology, Southern Methodist University, Dallas, TX 75275. a taste/odor compound (chocolate milk and banana odor) with lithium. A single chocolate milk test was then administered either 1 day or 21 days following conditioning. In both experiments, chocolate milk conditioning was less at a 1-day retention interval than at a 21 -day retention interval. The authors interpreted these results in the context of retrieval failure following compound-stimulus conditioning, implying that similar changes would not be expected with single-element aversions. Specifically, they suggested that the overshadowed taste is more difficult to retrieve 1 day after conditioning than it is 21 days after conditioning. The mechanisms of this retrieval failure at the more proximal conditioning-to-testing interval, however, were not specified, nor was the possibility considered that the more pronounced overshadowing at the 1-day retention interval was due instead to incomplete consolidation of the conditioning sequence.

The purpose of the present experiments was to analyze the retention of taste aversions in a broader context and to settle more clearly on the types of mechanisms that might mediate the retention of these aversions. Experiment 1 was designed to study the retention of a singleelement taste aversion at the 1-and 21-day intervals used by Kraemer et al. (1988) and J. S. Miller et al. (1990). Although no significant changes in the retention of a single-element taste aversion were reported in their experiments, mean aversions were weaker in all singleelement groups at the 1-day interval than at the 21-day interval. This is consistent with the findings of Batsell and M. R. Best (1990) for retention intervals ranging from 1 day to 10 days and suggests that the processes mediating retention changes in compound conditioning may also apply to single-element conditioning. 


\section{EXPERIMENT 1}

To determine if the retention of a saccharin aversion 21 days after conditioning appears different from the retention after 1 day, a three-group experiment was conducted. All animals drank saccharin during conditioning and, $10 \mathrm{~min}$ later, received injections of lithium chloride. One group was tested $24 \mathrm{~h}$ after conditioning, whereas the second was tested under identical conditions 21 days after conditioning. An additional group of animals was also tested 21 days after conditioning but received a second lithium injection $24 \mathrm{~h}$ prior to the test. This manipulation served as an unconditioned stimulus (US) postexposure and controlled for any possible illness effects determining test-day intakes in the group tested 1 day after conditioning. Previous research has demonstrated that US postexposure in a flavor-aversion paradigm either has no effect on the strength of the taste aversion (e.g., Brookshire \& Brackbill, 1976; Holman, 1976; Riley, Jacobs, \& LoLordo, 1976) or attenuates the aversion (e.g., Colby \& Smith, 1977; Mikulka, Leard, \& Klein, 1977). It does not strengthen the taste aversion.

\section{Method}

Subjects and Procedure. The subjects were 28 naive male Holtzman rats, born and reared in the Southern Methodist University animal colony. All subjects weighed between $250-450 \mathrm{~g}$. Animals were housed singly in standard Wahmann cages and had free access to Purina Rat Chow. The vivarium was on a 12:12-h light:dark cycle, with the light cycle beginning at $0600 \mathrm{~h}$. All rats were kept on a water deprivation schedule for 2 weeks prior to experimental manipulations and throughout the entire experiment. Each subject received access to $\mathbf{4 0} \mathrm{ml}$ of water for $20 \mathrm{~min}$ each day at approximately $1200 \mathrm{~h}$. The water (and all fluids) was presented in calibrated 50-ml polypropylene centrifuge tubes. The liquids for all manipulations were always presented in the home cage. All intakes were recorded to the nearest $0.1 \mathrm{ml}$.

The animals were matched into three groups based on their water intakes. Two groups [Groups R21 $(n=8)$ and R21-I $(n=10)$ ] were conditioned 21 days before testing, whereas the other group [Group R1 $(n=10)$ ] was conditioned 1 day before testing. Groups were conditioned on separate days but all were tested together. During conditioning, the animals would receive 10 -min access to $8 \mathrm{ml}$ of a $\mathbf{0 . 1 5 \%}$ sodium saccharin solution. Ten minutes after removal of the drinking bottles, these animals were given an intraperitoneal (i.p.) injection of $0.15 \mathrm{M}$ lithium chloride solution ( $\mathrm{LiCl}: 12 \mathrm{mg} / \mathrm{kg}$ of body weight). Although this dosage of $\mathrm{LiCl}$ was relatively weak, it produces substantial taste aversions in rats (e.g., Batson \& M. R. Best, 1982; M. R. Best \& Domjan, 1979; Domjan \& M. R. Best, 1977; Nachman \& Ashe, 1973). No maintenance fluids were given until $24 \mathrm{~h}$ later.

This procedure was used at both the 1-day and the 21-day conditioning intervals. To equate deprivation levels of the groups at the 1-day interval, Groups R21 and R21-I received access to $8 \mathrm{ml}$ of water, whereas Group R1 was conditioned with saccharin. When Group $R 1$ received its $\mathrm{LiCl}$ injection, Group R21-I received a second $\mathrm{LiCl}$ injection. This procedure was done to equate the aftereffects of illness for Groups R1 and R21-I at the time of testing. For testing, all animals received 20-min access to $30 \mathrm{ml}$ of saccharin. Testing was performed over 3 consecutive days at $1200 \mathrm{~h}$.

Finally, on Test Days 1 and 2, all animals received their daily water maintenance (i.e., access to $40 \mathrm{ml}$ of water for $20 \mathrm{~min}$ ) $5 \mathrm{~h}$ after testing. This procedure was used both to balance hydration effects across testing and to eliminate any potential health problems caused by excessive hydration. One effect of this procedure was that the animals were thirstier on Test Day 1 than on the other tests. However, since all group intakes were equated on the day prior to conditioning, the level of thirst should be equal in all groups and should not contribute to any between-group differences. In addition, this water maintenance should reduce the level of thirst on the latter test days and slow the rate of extinction.

Data analysts. In each experiment, multiple tests were conducted to eliminate any influence caused by aftereffects of illness or differential hydration on Test Day 1. As such, mixed analyses of variance (ANOVAs) were used for statistical interpretation. In addition, planned comparisons ( $t$ tests) were used to determine if differences existed between specific groups. The rejection criterion was set at 0.05 .

\section{Results}

The animals were matched into groups according to their water intakes for the 2 weeks prior to experimental manipulations. The groups' mean water intakes ranged from 20.96 to $21.1 \mathrm{ml}$. During conditioning, animals equally consumed the saccharin, as evidenced by the following means: $R 1=4.7 \mathrm{ml}, \mathrm{R} 21-\mathrm{I}=6.0 \mathrm{ml}$, and $\mathrm{R} 21=4.5 \mathrm{ml}$.

On Test Day 1, Group R1 drank more saccharin (11.01 ml) than either Group R21-I (2.83 ml) or Group R21 $(1.2 \mathrm{ml})$. On Test Day 2, the overall intake of saccharin increased, but the pattern of group differences remained intact (Group R1 = $19.9 \mathrm{ml}$, Group R21-I $=10.7 \mathrm{ml}$, and Group R21 $=6.4 \mathrm{ml}$ ). Finally, on Test Day 3, the animals appeared to have extinguished the saccharin aversion, since all groups drank similar amounts (Group R1 $=22.8 \mathrm{ml}$, Group R21-I $=21.8 \mathrm{ml}$, and Group R21 = $17.5 \mathrm{ml}$ ).

The mean saccharin consumption of the three groups averaged over the 3 days of testing is presented in Figure 1 . The $3 \times 3$ mixed ANOVA with groups as the betweengroup factor and test trials as the repeated measure confirmed that the groups differed $[F(2,25)=30.2]$. Planned

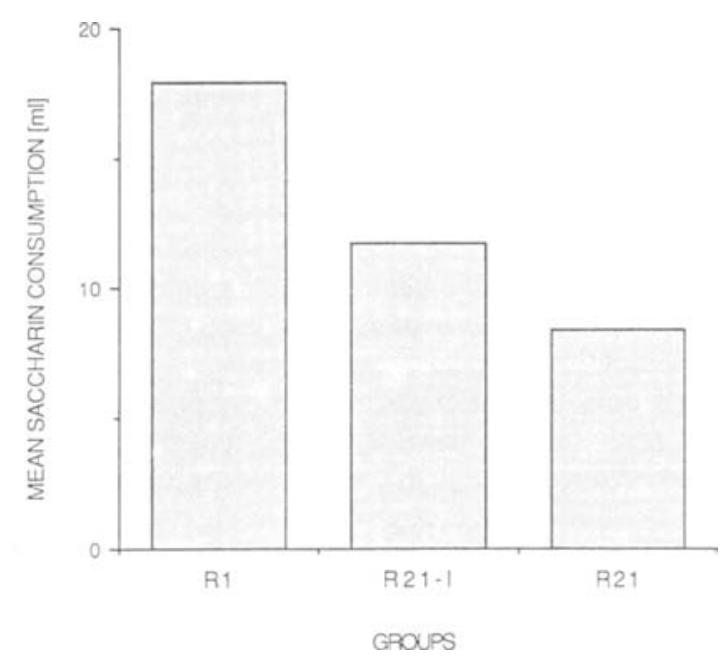

Figure 1. Mean sacchartn conournption in minilters averesed over

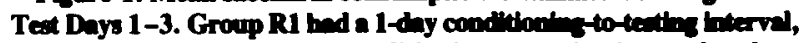
Group R21 -I had a 21-day condifionies-to-teathes Interval and recelved an unconditoned stmolves poctexpoure lajection $24 \mathrm{~h}$ prior to testing, and Group R21 had a 21-day conditontag-to-tenthe biterval. 
comparison analyses revealed that all groups differed significantly; Group R1 drank significantly more than Groups R21-I and R21, and Group R21-I drank significantly more than Group R21. The trials effect $[F(2,50)=173.2]$ and the groups $\times$ trials interaction $[F(4,50)=6.3]$ were both significant. The significant trials effect is expected, since it shows extinction of the saccharin aversion across the 3 test days. Also, the significant groups $\times$ trials interaction is not surprising, since different rates of extinction would be expected from groups with differing aversion strength. For example, on Test Day 1, the aversion of Group R1 is relatively weak compared with that of Group R21. Hence, one would expect the animals in Group Rl to extinguish their saccharin aversion more quickly than the animals in Group R21.

\section{Discussion}

It is clear from the results of Experiment 1 that saccharin aversions appear weaker when tested 1 day after conditioning than when tested 21 days after conditioning. It is also clear that the diminished aversions to saccharin 1 day after conditioning are not caused by transient influences such as illness aftereffects or hydration differences between the groups. This is demonstrated by the substantially stronger saccharin aversions in Group R21-I animals that received lithium 1 day prior to the test but that were also conditioned 21 days before testing. Even though the animals in Group R21-I drank significantly more than those in Group R21 over the averaged 3 days of testing, their saccharin intakes were not elevated to the level of Group R1, especially on Test Day 1, when the aftereffects of the $\mathrm{LiCl}$ injection would be most pronounced. Furthermore, it is not surprising that a US postexposure diminished the saccharin aversion of Group R21-I, because this effect has been previously reported by others (e.g., Colby \& Smith, 1977; Mikulka, Leard, \& Klein, 1977).

The pattern of results across the 3 test days also argues against the importance of transient effects in the outcomes of this experiment. If the temporary effects of the conditioning episode were disrupting the test up to 1 day later, these effects would have dissipated by the second and third tests, administered 48 and $72 \mathrm{~h}$ after conditioning. Instead, over the 3 days of testing, saccharin aversions in the animals conditioned 1 day prior to the initiation of testing were weaker than those in animals tested 21 days after conditioning.

In addition, the pattern of outcomes on the three saccharin tests argues against the proposition that the diminished aversions at the 1-day testing interval were caused by incomplete consolidation at the time of the initial test. If this were true, one might expect the aversions on the second and third tests to be stronger when consolidation of the aversions should be complete. This was not the case. A partial consolidation account of the 1-day data could only be defended if it were argued that the initial test extinguished the partially consolidated aversion and/or prevented further consolidation of this aversion.
Also, a contrast effect explanation of the current data can be discounted on the basis of previous research (Batsell \& M. R. Best, 1990). It is conceivable that the stronger aversions to saccharin at the 21-day testing interval are due to the animals" "surprise" in reencountering the saccharin following extensive exposure to water. However, Batsell and M. R. Best reported significantly stronger taste aversions at 3-, 5-, and 10-day retention intervals than at the 1-day interval. Although a contrast effect is a possible mechanism over the 21-day interval, it appears unlikely that this effect would be manifested over a 3- or 5 -day retention interval.

In the absence of viable alternative interpretations, perhaps the most compelling account for the data from Experiment 1 is retrieval failure. It is possible that the contextual cues present on the conditioning trial acquire associative strength that is extinguished during the interval between conditioning and testing. If these context- $\mathrm{LiCl}$ associations were assumed to compete, rather than summate, with the taste- $\mathrm{LiCl}$ association, they should provide more retrieval interference at the shorter retention interval, at which the conditioned properties of these contextual stimuli are stronger. Consequently, the saccharin aversions should appear weaker at this interval. In fact, others have shown that reducing stimulus competition can promote the detection of associations (Kaufman \& Bolles, 1981). Matzel, Schachtman, and R. R. Miller (1985) and Matzel, Shuster, and R. R. Miller (1987) demonstrated that when an element (i.e., a tone) of a compound was extinguished following conditioning, stronger suppression of the overshadowed element (i.e., a light) was observed, compared with a group that had not received extinction. This result is consistent with the "comparator hypothesis" of R. R. Miller and his colleagues (R. R. Miller \& Schachtman, 1985). According to this hypothesis, the magnitude of the conditioned response (CR) during testing is calculated by comparing the current associative strength of the conditioned stimulus (CS) with the current value of other stimuli (i.e., the training context) present during training. In fact, Kasprow, Schachtman, and Miller (1987) have demonstrated that extinction of the training context following conditioning does facilitate the CR to the target CS in a different testing environment. In the present experiment, the target taste would possess greater relative response potential after extinction of contextual associations with lithium than before extinction.

This retrieval interference analysis is particularly interesting in light of our increasing understanding of the role of contextual conditioning in the control of ingestional behavior. Although environmental stimuli are less readily associated with toxicosis than are tastes, associations can be formed between this class of stimuli and internal distress (e.g., P. J. Best, M. R. Best, \& Henggeler, 1977; J. S. Miller, McCoy, Kelly, \& Bardo, 1986; Westbrook \& Brookes, 1988). In addition, the presence of a taste stimulus on a conditioning trial is often reported to dishabituate contextual stimuli (M. R. Best \& Meachum, 
1986; Mitchell, Kirschbaum, \& Perry, 1975; Rudy, Rosenberg, \& Sandell, 1977). Consequently, it is reasonable to assume that a modicum of associative strength might accrue to the familiar home cage stimuli surrounding the conditioning encounter in the present experiment. Moreover, since these associations should be weak and therefore less likely to enter into higher order associations with the taste stimuli (M. R. Best, Batson, Meachum, Brown, \& Ringer, 1985), they might constitute particularly effective sources of retrieval interference in the performance of taste aversions.

We might also expect contextual interference to change if multiple conditioning trials are administered. Bonardi, Honey, and Hall (1990) failed to see evidence of context specificity in a flavor-aversion paradigm when only one conditioning trial was used. However, when multiple conditioning trials (i.e., five trials) occurred, context specificity of the taste aversion was observed. They proposed that the context-lithium associations served as cues that fostered, rather than interfered with, the retrieval of the flavor aversion. It is also possible that multiple conditioning trials establish associations between the context and the taste, thereby providing an opportunity for excitatory summation (M. R. Best et al., 1985). Such summation would reduce the ability to detect any associative interference provided by the context.

\section{EXPERIMENT 2}

The results of Experiment 1 indicate that taste aversions appear stronger when tested 21 days after conditioning than when they are tested 1 day after conditioning. This apparent increase in the strength of conditioning with increases in the conditioning-to-testing interval is similar to changes noted by Kraemer et al. (1988) and J. S. Miller et al. (1990) in the expression of overshadowing in a compound-conditioning flavor-aversion procedure. These investigators observed weaker aversions to the chocolate milk component of a chocolate milk/banana odor conditioning compound 1 day after conditioning than after a 21-day retention interval. In addition, in both of these experiments, mean intakes for all groups that underwent a conditioning episode were higher 1 day after conditioning than after 21 days. Experiment 2 was conducted in light of these findings and the parallel observation of Experiment 1 , in which single-element conditioning was used. By using the parameters of the preceding experiment, the presence of retention effects for overshadowing, similar to those observed for single-element conditioning, was evaluated.

The procedures for Experiment 2 paralleled those of Experiment 1. However, in addition to groups of rats that drank saccharin during conditioning, there were also groups that drank a compound solution consisting of saccharin and denatonium saccharide. These tastes were used because previous work indicates that saccharin reliably overshadows denatonium aversions (Davis, Best, \& Grover, 1988 ) and that aversions between these two tastes do not readily generalize to one another or punish the animals' drinking of either (Davis et al., 1990). Denatonium tests were then administered either 1 day or 21 days after conditioning. The animals from all groups were administered three tests. Extinction testing was conducted as a safeguard against errors of interpretation resulting from floor effects produced by the conditioning episode and to assure that the outcomes were not a function of processes operating on the initial test, 1 day after conditioning. Thus far, all the evidence for the dissipation of overshadowing and the attendant recovery of taste aversions at extended retention intervals is based on a single test (see Kraemer et al., 1988; Miller et al., 1990).

\section{Method}

The subjects were 40 naive male Holtzman rats, weighing approximately $235-385 \mathrm{~g}$. They were maintained under conditions identical to those described in Experiment 1.

The animals were matched into four groups of 10 based on their water intakes. Twenty animals were conditioned at each retention interval ( 1 day [Groups R1] or 21 days [Groups $\mathbf{R} 21$ ] prior to testing). On the conditioning day, 10 animals were in the denatonium group [DEN], and 10 animals were in the compound saccharin + denatonium group [SAC +DEN]. Thus, the four groups were the compound saccharin + denatonium group at 1 day (Group R1-SAC+ DEN), the denatonium group at 1 day (Group R1-DEN), the compound saccharin + denatonium group at 21 days (Group R21-SAC + $D E N$ ), and the denatonium group at 21 days (Group R21-DEN).

The DEN groups received $9 \mathrm{ml}$ of a $0.01 \%$ denatonium solution, whereas the compound SAC + DEN groups received $9 \mathrm{ml}$ of a $0.15 \%$ solution of saccharin mixed with denatonium. The animals had access to these fluids for $10 \mathrm{~min}$. Animals received toxicosis conditioning ( $\mathrm{LiCl}$ : i.p.) $10 \mathrm{~min}$ after the bottles were removed. No maintenance fluids were given until $24 \mathrm{~h}$ after conditioning. This conditioning procedure was used at both the 1-day and the 21 -day intervals. To equate deprivation levels of the $R 1$ and $R 21$ groups at the 1-day interval, Groups R21-DEN and R21-SAC + DEN received access to $9 \mathrm{ml}$ of water, whereas Groups R1-DEN and R1-SAC +DEN were conditioned with their respective target flavors.

All animals were tested on the same day. Testing consisted of giving all animals 20 -min access to $30 \mathrm{ml}$ of denatonium. Testing was conducted over 3 consecutive days. All manipulations occurred at $1200 \mathrm{~h}$. ANOVAs were used for statistical interpretation, with retention interval, liquid, and test trials as factors. Planned comparisons were used to determine the presence of overshadowing and to test for differences across retention intervals.

\section{Results}

The rats were matched into four groups prior to experimental manipulations. The mean water consumption of the groups ranged from $20.6 \mathrm{ml}$ to $20.8 \mathrm{ml}$. During conditioning, Groups R21-SAC + DEN and R1-SAC + DEN drank the saccharin-denatonium mixture, whereas Groups R21DEN and R1-DEN drank denatonium. The mean intakes on the conditioning trial were R1-SAC $+\mathrm{DEN}=6.07 \mathrm{ml}$, $\mathrm{R} 1-\mathrm{DEN}=4.52 \mathrm{ml}, \mathrm{R} 21-\mathrm{SAC}+\mathrm{DEN}=4.33 \mathrm{ml}$, and R21-DEN $=1.91 \mathrm{ml}^{1}$

On Test Day 1, differences in denatonium consumption were observed between the groups: Group R1-SAC + DEN drank a substantial amount of denatonium $(16.9 \mathrm{ml})$, whereas the other groups drank either intermediate amounts (Group R1-DEN = $3.38 \mathrm{ml}$ and Group R21-SAC +DEN 
$=2.38 \mathrm{ml}$ ) or little denatonium (Group R21-DEN $=$ $0.44 \mathrm{ml}$ ). On Test Day 2, this pattern of responding continued, as Group R1-SAC + DEN consumed copious amounts of denatonium $(18.5 \mathrm{ml})$ relative to the other groups (Group R1-DEN $=8.77 \mathrm{ml}$, Group R21-SAC +DEN = $6.82 \mathrm{ml}$, and Group R21-DEN = 1.1). On Test Day 3, the groups began to extinguish their denatonium aversions as greater amounts were consumed (Group R1-SAC+DEN $=17.1 \mathrm{ml}$, Group R1-DEN $=13.0 \mathrm{ml}$, Group R21$\mathrm{SAC}+\mathrm{DEN}=11.9 \mathrm{ml}$, and Group R21-DEN $=4.45 \mathrm{ml}$ ).

The mean denatonium intakes of the four groups averaged over the 3 days of testing are presented in Figure 2. Groups tested 1 day after conditioning drank considerably more than those tested 21 days after conditioning, and saccharin significantly overshadowed the denatonium aversion at both retention intervals. The ANOVA yielded significant retention interval $[F(1,36)=50.26]$ and liquid effects $[F(1,36)=36.78]$, but the interaction was not significant $[F(1,36)=2.94]$. The planned comparisons confirmed that overshadowing occurred at both the 1- and 21 -day intervals. The analyses also revealed that the consumption of Group R21-DEN was significantly depressed relative to that of Group R1-DEN, replicating the results of Experiment 1.

The trials effect $[F(2,72)=30.56]$ and the retention interval $\times$ liquid $\times$ trials interaction were significant $[F(2,72)=12.7]$; the retention interval $\times$ trial $[F(2,72)=$ 1.9] and the liquid $x$ retention interval interactions $[F(2,72)=1.2]$ were not significant. Again, the significant trials effect appears to have been caused by the extinction of the denatonium aversion over the 3 days of testing; the three-way interaction represents the differential extinction of the denatonium aversions across the 1-day and 21-day groups.

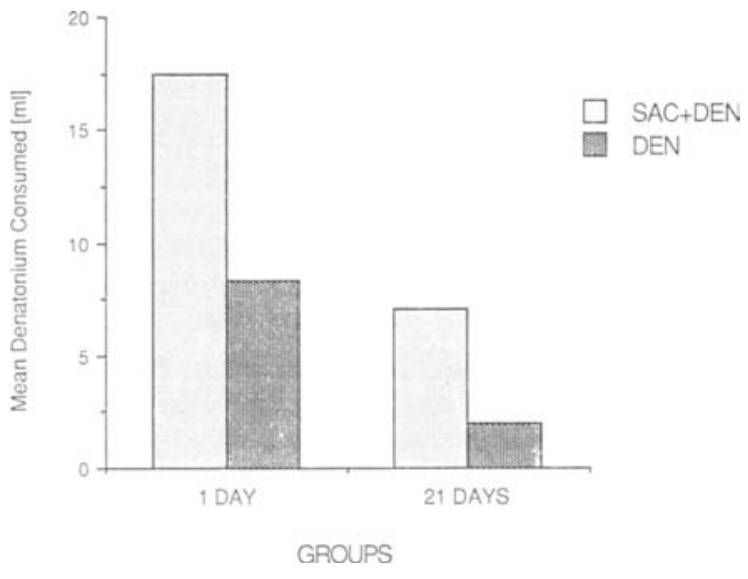

Figure 2. Mean denatonium consumption in milliliters of Groups R1-SAC + DEN, R1-DEN, R21-SAC + DEN, and R21-DEN avergeged over Tea Days 1-3. Groups R1-SAC +DEN and R21-SAC+ DEN were aversively condidoned with the saccharth/denton'um mixture, wheress Groups R1-DEN and R21-DEN were averdively conditioned only to dentontum. Groups R1-SAC+DEN and R1-DEN were conditioned 1 day before testing, and Groups R21-SAC +DEN and R21-DEN were conditioned 21 days before testing.

\section{Discussion}

Several aspects of these results deserve emphasis. First, the data from the three denatonium tests combined revealed that denatonium was overshadowed by saccharin at both retention intervals, in contrast to the Test Day 1 results of Kraemer et al. (1988) and J. S. Miller et al. (1990). This result points to the value of conducting multiple tests when studying stimulus interactions. It is possible that multipie tests would also have revealed overshadowing at the 21-day retention interval in the reports of Kraemer et al. and J. S. Miller et al.

Another result of Experiment 2 that differs from those of Kraemer et al. (1988) and J. S. Miller et al. (1990) was the effect on single-taste intakes of a conditioning trial $24 \mathrm{~h}$ prior to the test. Intakes of this taste were significantly higher 1 day after conditioning than 21 days after conditioning in both the DEN and the SAC+DEN groups. This is noteworthy, since it suggests that similar factors mediate the retrieval of both single-element and compoundtaste aversions. If so, then the theoretical account of these results must accommodate both single-element and compound changes. Regardless of the processes that produced increased drinking of denatonium $24 \mathrm{~h}$ after conditioning, it seems unlikely that the aversion gradually increased with time. Instead, it appears that the aversions at the 1-day interval were obscured by some effect of the conditioning session $24 \mathrm{~h}$ earlier.

As with the results of Experiment 1, retrieval interference provides a possible account of the test data from the present experiment. It is possible that overshadowing is more readily detected at the 1-day retention interval because the contextual stimuli present during conditioning have not yet undergone extinction and therefore are more likely to interfere with the taste aversion. In contrast, at the 21-day retention interval, the associative strength of the contextual stimuli should be extinguished and therefore provide minimal disruptive influence on the performance of the taste aversion. This implies that overshadowing should be more apparent in testing situations that contain additional excitatory elements. However, overshadowing should be present to some degree at all testing intervals.

\section{EXPERIMENT 3}

An alternative account of the elevated consumption of denatonium 1 day after conditioning is that it reflects an unconditioned change in preference for this taste across the retention interval. It is possible, for example, that a 1-day interval between initial exposure to denatonium and its test produces a decrement in neophobia to this taste that dissipates at the later exposure-to-test interval (i.e., 21 days; e.g., see Domjan, 1977). This was investigated in the present experiment. For this assessment, groups of animals drank either denatonium or a mix of saccharin and denatonium and were then tested with denatonium 1 day or 21 days after this initial exposure. 


\section{Method}

The subjects were 31 naive male Holtzman rats, weighing between $250-400 \mathrm{~g}$, from the Southern Methodist University animal colony. All animals were maintained under the conditions followed in Experiments 1 and 2 . The mean intakes of the water deprivation procedure were used to match the animals into four groups. The groups of this experiment were essentially the same as those in Experiment 2 [R1-SAC + DEN $(n=8)$, R1-DEN $(n=7)$, R21-SAC + DEN $(n=8)$, and R21-DEN $(n=8)]$. In all respects, these groups received the same treatment as the groups of Experiment 2, except that instead of receiving the lithium injection, these groups received a sham injection of $0.9 \%$ isotonic saline after exposure to their respective tastes. One other change was implemented: Conditioningday fluid exposure was reduced to $6 \mathrm{ml}$ to approximate more closely the mean conditioning intakes of the groups in Experiment 2. Again, testing consisted of access to $30 \mathrm{ml}$ of denatonium over 3 days, and statistical analysis was also similar to Experiment 2.

\section{Results and Discussion}

Animals were matched to four groups according to their mean intakes during water deprivation. The mean group intakes ranged from 17.7 to $17.8 \mathrm{ml}$. During conditioning, the group mean intakes were as follows: R1-SAC + DEN $=4.5 \mathrm{ml}, \mathrm{R} 1-\mathrm{DEN}=5.1 \mathrm{ml}, \mathrm{R} 21-\mathrm{SAC}+\mathrm{DEN}=$ $3.55 \mathrm{ml}$, and R21-DEN $=5.7 \mathrm{ml}$.

On Test Day 1, all groups drank approximately the same amount of denatonium (R1-SAC + DEN $=18.2 \mathrm{ml}$, $\mathrm{R} 1$-DEN $=19.2 \mathrm{ml}, \mathrm{R} 21-\mathrm{SAC}+\mathrm{DEN}=19.8 \mathrm{ml}$, and R21-DEN $=16.9 \mathrm{ml}$ ). On Test Day 2, all groups slightly decreased intake of denatonium $(R 1-S A C+D E N$ $=17.6 \mathrm{ml}, \mathrm{R} 1-\mathrm{DEN}=16.9 \mathrm{ml}, \mathrm{R} 21-\mathrm{SAC}+\mathrm{DEN}=$ $16.2 \mathrm{ml}$, and R21-DEN $=15.2 \mathrm{ml}$ ). Finally, on Test Day 3, the trend of decreasing denatonium consumption continued without exception across the groups (RI$\mathrm{SAC}+\mathrm{DEN}=16.2 \mathrm{ml}, \mathrm{R} 1-\mathrm{DEN}=15 \mathrm{ml}, \mathrm{R} 21-\mathrm{SAC}+$ DEN $=15.9 \mathrm{ml}$, and $\mathrm{R} 21-\mathrm{DEN}=13.4 \mathrm{ml}$ ).

The mean denatonium intakes of the four groups averaged over the 3 days of testing are displayed in Figure 3 . All groups drank similar amounts across testing. The ANOVA revealed that no significant effects existed for retention interval $[F(1,27)=1.2]$, liquid $[F(1,27)=2.0]$, or the retention interval $\times$ liquid interaction $[F(1,27)=$ 1.1]. Planned comparisons confirmed that no significant differences existed between specific pairs of groups.

Of the other analyses, only the trials effect was significant $[F(2,54)=11.8]$. All of the other analyses were not significant: retention interval $\times$ trials interaction $[F(2,54)$ $<1]$, liquid $\times$ trials interaction $[F(2,54)<1]$, and retention interval $\times$ liquid $\times$ trials interaction $[F(2,54)<1]$. Interestingly, analysis of the trials effect showed a surprising trend: Consumption of denatonium decreased as trials increased. Since neither retention interval nor liquid interacted with this trials effect, it can be concluded that this effect is caused by something other than the experimental manipulations. A probable source for this downward consumption trend is that the animals received their daily water maintenance $5 \mathrm{~h}$ after testing; this reduced their consumption of denatonium on the subsequent test days.

In Experiment 3, animals were exposed to either denatonium or a saccharin/denatonium mixture and then allowed

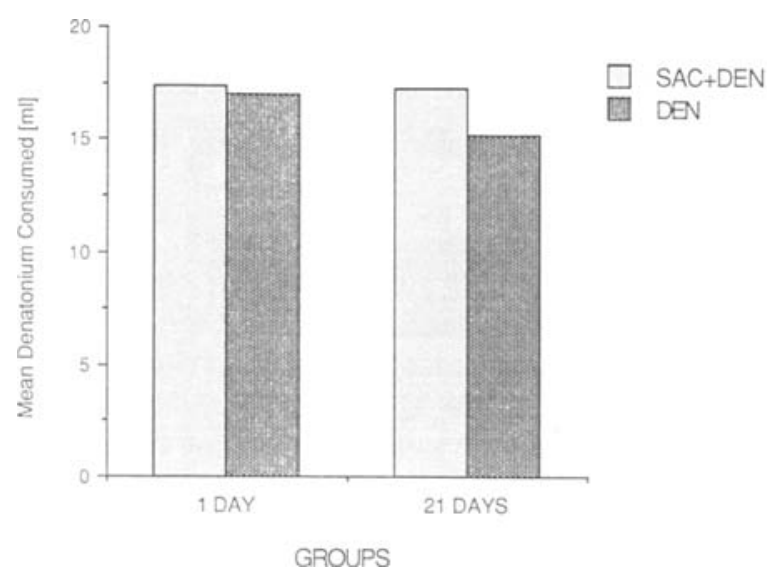

Figure 3. Mean denatonium consumption in milliliters of Groups R1-SAC + DEN, R1-DEN, R21-SAC + DEN, and R21-DEN averaged over Test Days 1-3. Groups R1-SAC + DEN and R21-SAC + DEN were sham conditioned with the sacharin/denetonhum mixture, wherens Groups R1-DEN and R21-DEN were sham conditioned only to denatonium. Groups R1-SAC +DEN and R1-DEN were conditioned 1 day before testing, and Groups R21-SAC +DEN and R21-DEN were conditioned 21 days before testing.

to drink denatonium again after one of two retention intervals ( 1 day or 21 days). This experiment sought to determine if changes in the rats' consumption of denatonium differentially occurred across these retention intervals. No differences between groups were observed. Thus, the results of Experiment 3 suggest that the differential aversions across time observed in Experiment 2 were not produced by unconditioned changes in taste preference.

\section{EXPERIMENT 4}

Intakes of the test fluid were higher $24 \mathrm{~h}$ after a conditioning episode than they were 21 days later. Such elevated intake soon after the conditioning session facilitates the demonstration of overshadowing, as indicated by the large magnitude of denatonium overshadowing detected at the 1-day test interval in the group receiving saccharin and denatonium on the conditioning trial (see Experiment 2 ). These proximal elevations may also have implications for the measurement of taste-mediated potentiation.

A growing literature (for a review, see LoLordo \& Droungas, 1989) documents the ability of a taste stimulus to enhance or potentiate the aversion to a second, concomitant stimulus in an ingestional-aversion procedure. Such taste-mediated ingestional potentiation has been reported for odors, auditory stimuli, visual stimuli, and contextual stimuli (e.g., M. R. Best, Brown, \& Sowell, 1984; Bouton, Dunlap, \& Swartzentruber, 1987; Davis et al., 1988; Davis et al., 1990; Ellins, Cramer, \& Whitmore, 1985; Galef \& Osborne, 1978; Rusiniak, Hankins, Garcia, \& Brett, 1979). In the Davis et al. (1988) experiments (see also Davis et al., 1990), rats received the same saccharin/denatonium conditioning mixture used in Ex- 
periments 2 and 3 of this report. Consistent with the results of these experiments, denatonium aversions were significantly weaker in animals that consumed the compound during conditioning. Saccharin tests following compound conditioning, however, revealed enhanced conditioning of this element relative to saccharin aversions following single-element conditioning of saccharin. Experiment 4 was specifically designed to evaluate this denatoniummediated saccharin potentiation at the intervals used to evaluate denatonium overshadowing in Experiment 2 (i.e., 1 day and 21 days). This experiment should be particularly enlightening because potentiated aversions have not been studied at differing retention intervals.

Potentiation procedures should be particularly useful in evaluating the viability of a retrieval-interference analysis of retention differences in the performance of a taste aversion. Because potentiation results in an enhanced aversion, it would be expected that this phenomenon should be more evident at longer rather than shorter retention intervals. This is because any competing contextual associations should be extinguished at the longer intervals and should therefore provide minimal retrieval interference for the taste.

\section{Method}

The subjects were 40 naive male Holtzman rats, approximately $320-550 \mathrm{~g}$. Conditions for animal maintenance were the same as in the previous experiments. The rats were matched into four groups of 10 by their water intakes, with 20 animals conditioned 21 days before testing and the other 20 animals conditioned $24 \mathrm{~h}$ prior to testing. Again, the group designations were the following: compound denatonium + saccharin group at 1 day (Group R1-DEN+SAC), saccharin group at 1 day (Group R1-SAC), compound denatonium + saccharin group at 21 days (Group R21-DEN + SAC), and a saccharin group at 21 days (Group R21-SAC). At each retention interval, the single-taste groups received 10-min access to $9 \mathrm{ml}$ of $0.15 \%$ saccharin, whereas the compound-taste groups received equal access to $9 \mathrm{ml}$ of the denatonium + saccharin mixture before aversive conditioning. This procedure was used at both retention intervals, except fluid deprivation levels were equated on 1-day conditioning. All animals were tested over the same 3 days with $30 \mathrm{ml}$ of saccharin for $20 \mathrm{~min}$. All manipulations occurred at $1100 \mathrm{~h}$. Statistical analyses were the same as in Experiment 2.

\section{Results}

The rats' water deprivation intakes were used to match them into groups prior to any experimental manipulations. Group means ranged from 20.53 to $21.27 \mathrm{ml}$. The mean conditioning intakes for the four groups were the following: $R 1-S A C=8.01 \mathrm{ml}, \mathrm{R} 1-\mathrm{DEN}+\mathrm{SAC}=7.26 \mathrm{ml}$, $\mathrm{R} 21-\mathrm{SAC}=8.36 \mathrm{ml}$, and $\mathrm{R} 21-\mathrm{DEN}+\mathrm{SAC}=5.61 \mathrm{ml}$.

On Test Day 1, the 1-day groups drank considerably more saccharin than the 21-day groups $(\mathrm{R} 1-\mathrm{SAC}=4.49 \mathrm{ml}$, $\mathrm{R} 1-\mathrm{DEN}+\mathrm{SAC}=5.04 \mathrm{ml}, \mathrm{R} 21-\mathrm{SAC}=1.55 \mathrm{ml}$, and $\mathrm{R} 21-\mathrm{DEN}+\mathrm{SAC}=0.84 \mathrm{ml})$. On Test Day 2, this pattern of results continued, as the 1-day groups showed rapid extinction of the palatable saccharin solution (R1-SAC = $16.6 \mathrm{ml}, \mathrm{R} 1-\mathrm{DEN}+\mathrm{SAC}=16 \mathrm{ml}, \mathrm{R} 21-\mathrm{SAC}=6.5 \mathrm{ml}$, and R21-DEN +SAC = 3.3 ml). On Test Day 3, both 1day groups and the saccharin-only group at the 21-day re- tention interval drank large amounts, whereas Group R21 DEN + SAC still retained a strong saccharin aversion. Group means were the following: $\mathrm{R} 1-\mathrm{SAC}=21.9 \mathrm{ml}$, $\mathrm{R} 1-\mathrm{DEN}+\mathrm{SAC}=20.2 \mathrm{ml}, \mathrm{R} 21-\mathrm{SAC}=18.5 \mathrm{ml}$, and $\mathrm{R} 21-\mathrm{DEN}+\mathrm{SAC}=9.92 \mathrm{ml}$.

Figure 4 presents the mean saccharin intakes of the four groups averaged over Test Days 1-3. Two major results are obvious from this graph. First, the 1-day groups drank substantially more than the 21-day groups. Second, potentiation of the saccharin aversion occurred at the 21-day interval but not at the 1-day interval. The ANOVA over Test Days 1-3 confirmed not only retention interval differences $[F(1,36)=40.6]$ but also a significant liquid effect $[F(1,36)=4.2]$; the interaction effect was not significant $[F(1,36)=2.4]$. Specific planned group comparisons revealed that at the 21-day interval, the compound group drank significantly less than the single-element group; however, significant differences were not evident at the 1-day interval. Additionally, the differences between the saccharin-only groups paralleled the single-element results of Experiments 1 and 2: Group R1-SAC drank significantly more than Group R21-SAC over testing. Again, altering the retention interval affected the results of both single-element and compound-element taste conditioning.

The ANOVA further revealed significant trials $[F(2,72)$ $=174.1]$, retention interval $\times$ trial interaction $[F(2,72)$ $=12.5]$, and liquid $\times$ trials interaction $[F(2,72)=5.3]$; the retention interval $\times$ liquid $x$ trials interaction was not significant $[F(2,72)=1.8]$. The significant trials and retention $\times$ trials interaction effects are not surprising considering the similar results of Experiments 1 and 2. All groups' aversions extinguished over the 3 test days, and the rate of extinction was different for the 1- and 21-day groups. Of interest in this experiment is the significant liquid $x$

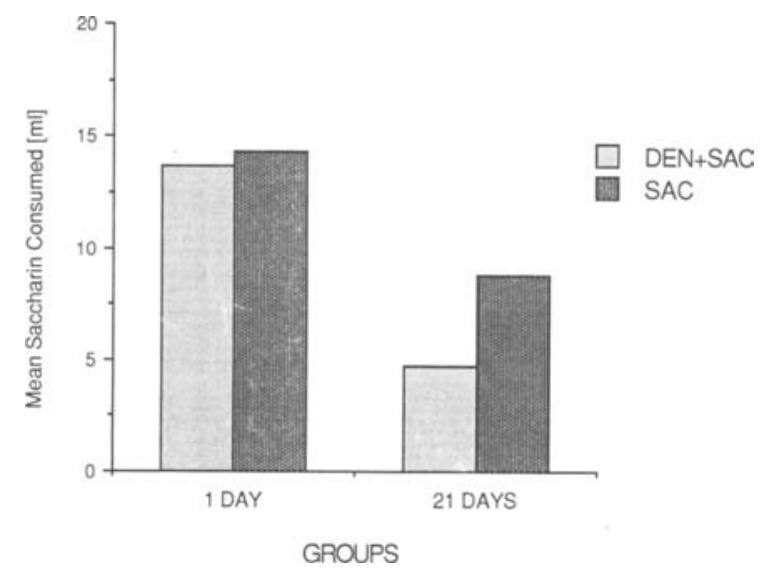

Figure 4. Mean saccharin consumption in milliliters of Groups R1-DEN + SAC, R1-SAC, R21-DEN +SAC, and R21-SAC averaged over Test Days 1-3. Groups R1-DEN +SAC and R21-DEN+ SAC were aversively conditioned wh the denatondum/eacherin mixture, wherees Groups R1-SAC and R21-SAC were aversively conditioned only to sacchnrin. Groups RI-DEN+SAC and R1-SAC were conditioned 1 day before testing, and Groups R21-DEN +SAC and R21-SAC were conditioned 21 days before testing. 
trials interaction in pointing to the strength of the potentiated saccharin aversion at the 21-day retention interval. A simple-effects analysis of the liquid effect on each of the test days reveals that intake differences increase as trials increase: Test Day $1[F(1,35)<1]$, Test Day $2[F(1,35)$ $=1.6]$, and Test Day $3[F(1,35)=6.6]$. It is suggested from these results that group differences were obscured by a floor effect on Test Day 1-both Groups R21-SAC and R21-DEN + SAC had strong aversions. However, over multiple testing trials, the aversion of Group R21-SAC extinguished more quickly and differences caused by conditioning liquid were detected.

\section{Discussion}

Two of the outcomes from the saccharin tests of Experiment 4 are worth discussing. In agreement with the testday data of Experiments 1 and 2, tests administered 1 day after conditioning resulted in greater intakes of the test fluid than did tests conducted 21 days after conditioning. This was true for rats conditioned either with saccharin alone (Groups SAC) or with the saccharin/denatonium compound (Groups SAC+DEN). Secondly, significant denatonium-mediated potentiation of the saccharin aversion was observed only at the 21-day conditioning-totesting interval.

The fact that intakes were elevated at the 1-day interval throughout a 3-day testing sequence indicates that these elevations were not caused by the refractory effects of the conditioning episode on the initial test. As in Experiments 1 and 2, this outcome eliminates either the substantial influences of incomplete consolidation or the refractory effects of toxicosis and hydration deficits on Test 1. Again, this implicates retrieval differences at the two intervals. In this regard, it is possible that rudimentary associations between the context and lithium interfere at least partially with the demonstration of the saccharin aversion during the tests at 1-day retention intervals. This is a particularly intriguing possibility given the evidence that pairing a novel taste with toxicosis in a familiar environment can dishabituate the contextual stimuli (Best \& Meachum, 1986; Mitchell et al., 1975; Rudy et al., 1977). At 21-day retention intervals, these context- $\mathrm{LiCl}$ associations should be extinguished by virtue of the extensive postconditioning exposure to the home cages. This should reduce retrieval interference, thereby resulting in an apparently stronger aversion to the saccharin at this retention interval.

The present experiment is also noteworthy because it is the first report of the relationship between retention interval and the expression of potentiation. Miller et al. (1990, Experiment 2) tested the odor component of a taste-odor compound following conditioning at 1- and 21-day retention intervals. However, their results cannot be legitimately compared with ours because there was no evidence of taste-mediated potentiation at either retention interval. Also, although a retrieval-competition interpretation might predict that the potentiated saccharin aversion at the 21-day interval would be stronger than its counterpart at the 1-day interval, it would not suggest that taste- mediated potentiation is not detectable at a 1-day testing interval. In fact, denatonium-mediated saccharin potentiation has been reported at a 1-day retention interval following stimulus preexposure and two-bottle testing (Davis et al., 1988). Instead, the current results suggest that the demonstration of taste-mediated potentiation will be more difficult at shorter retention intervals, particularly when the procedures (i.e., limited CS intakes, one-bottle testing) are likely to produce retrieval interference.

\section{EXPERIMENT 5}

An additional experiment was conducted to determine if any of the changes in the consumption of saccharin after 1-day and 21-day retention intervals were caused by unconditioned shifts in preference. All groups and procedures were identical to those used in Experiment 4, except that the animals were injected with isotonic saline on the conditioning episode instead of lithium.

\section{Method}

Thirty-one naive male Holtzman rats, weighing between 250 $400 \mathrm{~g}$, were matched into four groups based on their mean water intakes during deprivation training. Groups were designated similarly to those in Experiment 4. Basic animal maintenance was the same as that noted in the previous experiments. The procedure of this experiment mirrored that of Experiment 4, with the exception that animals in Experiment 4 were injected with lithium to promote aversive conditioning to the target taste(s), whereas animals in Experiment 5 received a sham injection of $0.9 \%$ isotonic saline. Again, all groups were given access to $6 \mathrm{ml}$ at conditioning so they would equal the lowest mean group intake of Experiment 4. Testing and statistical analyses were also the same as previously stated.

\section{Results and Discussion}

No differences in water consumption existed between the groups; all group means were $17.7 \mathrm{ml}$. During conditioning, all groups drank roughly the same amount, as demonstrated by the following means: Group R1-DEN + SAC $=3.8 \mathrm{ml}(n=8)$, Group R1-SAC $=4.8 \mathrm{ml}$ $(n=7)$, Group R21-DEN $+\mathrm{SAC}=3.5 \mathrm{ml}(n=8)$, and Group R21-SAC $=5.3 \mathrm{ml}(n=8)$.

The mean saccharin intakes of the four groups averaged over Test Days 1-3 are represented in Figure 5. On Test Day 1, the four groups drank approximately the same amount of saccharin (Group R1-DEN +SAC $=20.3 \mathrm{ml}$, Group R1-SAC = $19.6 \mathrm{ml}$, Group R21-DEN + SAC = $18.1 \mathrm{ml}$, and Group R21-SAC $=18.76 \mathrm{ml}$ ). By Test Day 2, all groups increased their consumption of saccharin (Group R1-DEN + SAC $=21.6 \mathrm{ml}$, Group R1-SAC $=20.8 \mathrm{ml}$, Group R21-DEN +SAC $=21.7 \mathrm{ml}$, and Group R21-SAC $=22.6 \mathrm{ml}$ ). Interestingly, on Test Day 3, all groups decreased their consumption of saccharin from the previous test (Group R1-DEN +SAC = $18.5 \mathrm{ml}$, Group R1-SAC $=18.5 \mathrm{ml}$, Group R21$\mathrm{DEN}+\mathrm{SAC}=18 \mathrm{ml}$, and Group R21-SAC $=18.5 \mathrm{ml}$ ).

An ANOVA was performed with retention interval, liquid, and test trials as factors. The trials effect was significant $[F(2,54)=10]$. No other significant effects were 


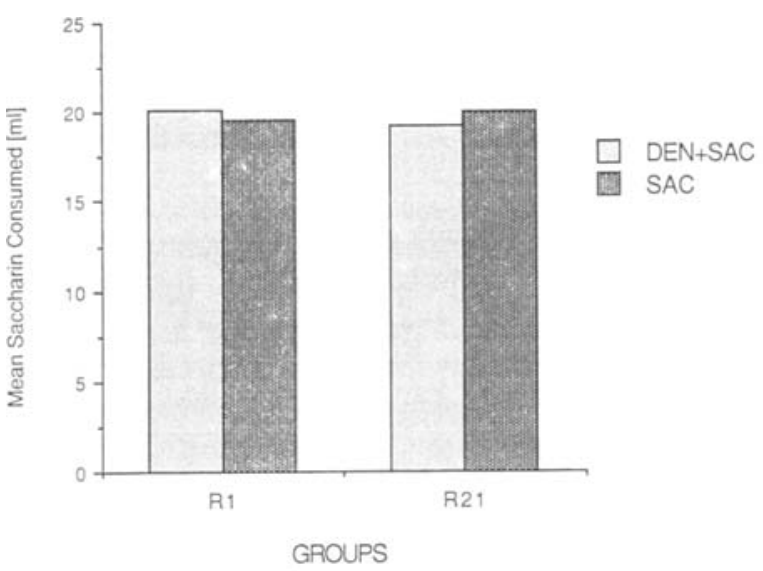

Figure 5. Mean saccharin consumption in milliliters of Groups R1-DEN + SAC, R1-SAC, R21-DEN + SAC, and R21-SAC averaged over Test Days 1-3. Groups R1-DEN + SAC and R21-DEN+ SAC were sham conditioned with the denatonium/saccharin mixture, whereas Groups R1-SAC and R21-SAC were sham conditioned only to saccharin. Groups R1-DEN +SAC and R1-SAC were conditioned 1 day before testing, and Groups R21-DEN +SAC and R21-SAC were conditioned 21 days before testing.

detected: retention interval $[F(1,27)<1]$, liquid $[F(1,27)$ $<1]$, retention interval $\times$ liquid interaction $[F(1,27)<$ 1], retention interval $\times$ trials interaction $[F(2,54)=1.0]$, liquid $\times$ trials interaction $[F(2,54)<1]$, and retention interval $\times$ liquid $\times$ trials interaction $[F(2,54)<1]$. The trials effect observed in this experiment was not a typical extinction curve but, rather, represented an increase in consumption from Day $1(19.3 \mathrm{ml})$ to Day $2(21.9 \mathrm{ml})$ and a subsequent decrease on Day $3(18.6 \mathrm{ml})$. Since neither the retention interval $\times$ trials interaction nor the liquid $\times$ trials interaction was significant, it can be concluded that the mechanism underlying these changes is not related to the manipulated variables but reflects a variable acting equally upon all groups. It is suggested that the changes in this experiment are similar to those in Experiment 3: Throughout the testing schedule, the animals' level of deprivation decreased as they received fluid during both testing and water maintenance later each day.

Overall, the results of this experiment are similar to those of Experiment 3. These control experiments were conducted to insure that the differences in response to denatonium and saccharin observed in Experiments 2 and 4 , respectively, did not occur because of unconditioned changes in taste preference across the 21-day retention interval. In neither Experiment 3 nor Experiment 5 was any change in preference for either liquid observed after the 21-day retention interval. It can be concluded that the diminished intakes observed at the 21-day testing interval in the previous experiments represent differences in the strength of conditioned aversion.

\section{EXPERIMENT 6}

The results of Experiments 1, 2, and 4 demonstrate that the strength of a single-element taste aversion increases as the conditioning-to-testing interval increases. In each of those experiments, groups tested $24 \mathrm{~h}$ after conditioning had significantly weaker aversions than comparably conditioned groups with a 21-day retention interval. It is also suggested that these differential aversions are not the result of various nonassociative mechanisms (i.e., unequal hydration, illness aftereffects, changes in flavor preferences over time). Instead, Experiments 1, 2, and 4 implicate an underlying associative mechanism that mediates this effect. One account that can satisfactorily integrate these results, along with the overshadowing and potentiation results of Experiments 2 and 4, is a retrievalcompetition explanation. Assuming that the presence of a novel flavor acts to dishabituate the familiar home cage and provides the possibility of associations between the environment and $\mathrm{LiCl}$, the retrieval-competition explanation posits that when the test occurs after the shorter retention interval, these environmental associations should interfere with the retrieval of the taste association and produce a weaker taste aversion. However, at the longer (21-day) retention interval, such environmental associations should be extinguished and should not interfere with the testing of the taste aversion.

The simplest method to test the adequacy of the retrieval-competition theory would be manipulation of the environmental associations during the conditioning-totesting interval. Specifically, preventing extinction of these environmental associations by removing the animals from the conditioning environment prior to the test should leave the possibility of retrieval competition intact. Animals treated in this manner should therefore evidence weaker taste aversions than animals that undergo environmental extinction. In turn, environmental extinction should allow an assessment of the taste aversion uncontaminated by strong retrieval competition.

Experiment 6 was designed to investigate this underlying assumption of the retrieval-competition hypothesis. Groups of rats were conditioned at either a short or a long retention interval. Following conditioning, one group of animals at each retention interval was placed in a second environment that differed from the familiar home cage. These animals received no exposure to their home cage until testing, whereas the other groups spent the entire conditioning-to-testing interval in their home cages. It is important to note that the animals need not be present in the conditioning environment when they experience the lithium-produced illness. It has been demonstrated that taste aversions are not decremented when, immediately after conditioning, the animals are placed in a chamber separate from the conditioning environment (Batson \& P. J. Best, 1979). An added feature of the retrievalcompetition interpretation within this design is that it controls for a time-dependent explanation for the results of the previous experiments. The retrieval-competition explanation is based on environmental extinction that may occur over time (e.g., 21 days), but it is not specifically dependent on the length of the interval. Instead, short and long intervals should produce similar aversions, provided that differential environmental associations do not exist 
in either case. In this regard, since Batsell and M. R. Best (1990) demonstrated that taste aversions tested 3, 5, or 10 days following conditioning were relatively equal, an intermediate interval (6 days) was chosen for the longer retention interval in the present experiment.

\section{Method}

The subjects were 44 naive male Holtzman rats, weighing approximately $250-350 \mathrm{~g}$. All housing and experimental conditions were the same as in the previous experiments. The rats were on a water deprivation schedule for 2 weeks prior to any experimental manipulations and were matched into four groups according to their mean daily water intake over an 8-day period. The groups were differentiated by their retention interval ( 6 days vs. 1 day) and by their postconditioning environmental experience (environmental extinction vs. no environmental extinction). Thus, the four groups consisted of the following: 6-day environmental extinction (6E), 6-day no environmental extinction (6N), 1-day environmental extinction (1E), and 1-day no environmental extinction (1N).

Groups $6 \mathrm{E}$ and $6 \mathrm{~N}$ were given access to $8 \mathrm{ml}$ of saccharin for $10 \mathrm{~min}$ in their home cages; $10 \mathrm{~min}$ later, they were injected with $\mathrm{LiCl}$. The members of Group $6 \mathrm{~N}$ were then transferred to a second environment, which consisted of $25 \times 29 \times 15 \mathrm{~cm}$ polypropylene mouse breeding cages fitted with steel lids and placed sideby-side on a rack in a dimly lit experimental room adjacent to the main vivarium. The animals in Group $6 \mathrm{E}$ were returned to their home cages. During this time, Groups $1 \mathrm{E}$ and $1 \mathrm{~N}$ were given their daily water maintenance in their home cages. Over the next 5 days, all groups remained on the water deprivation schedule; however, Groups $6 \mathrm{E}, 1 \mathrm{E}$, and $1 \mathrm{~N}$ received their fluid in their home cages, whereas Group $6 \mathrm{~N}$ received water in the mouse breeding cages.

One day before the test, all groups received $10-\mathrm{min}$ access to $8 \mathrm{ml}$ of fluid. During this time, Groups $6 \mathrm{E}$ and $6 \mathrm{~N}$ drank water in their home cages and in the breeding cages, respectively. Groups $1 E$ and $1 \mathrm{~N}$ drank saccharin and were aversively conditioned after a 10-min CS-US interval. Immediately following the $\mathrm{LiCl}$ injections, the animals in Group $1 \mathrm{~N}$ were placed in mouse breeding cages and transferred to the experimental room, whereas Group $1 \mathrm{E}$ animals were returned to their home cages. No maintenance fluid was given over the next $24 \mathrm{~h}$. Testing occurred over the next 3 days.

For testing, animals in Groups $6 \mathrm{~N}$ and $1 \mathrm{~N}$ were removed from their respective mouse breeding cages and placed in their home cages in the main vivarium. Next, all animals were given $30 \mathrm{ml}$ of saccharin for $20 \mathrm{~min}$. After this testing episode, Group $6 \mathrm{~N}$ and $1 \mathrm{~N}$ members were again placed in the breeding cages in the experimental room. Five hours later, all animals were given access to $40 \mathrm{ml}$ of water for $20 \mathrm{~min}$, either in the home cage or the breeding cage. This procedure was repeated over each of the next 2 test days. All saccharin intakes were measured to the nearest $0.1 \mathrm{ml}$.

\section{Results}

The animals were matched to groups according to their mean water intakes for an 8-day period preceding experimental manipulations. The group means ranged from $18.6 \mathrm{ml}$ to $18.7 \mathrm{ml}$. During conditioning, the four groups consumed comparable amounts of saccharin (Group $6 \mathrm{~N}$ $=6.3 \mathrm{ml}$, Group $6 \mathrm{E}=6.5 \mathrm{ml}$, Group $1 \mathrm{E}=6.4 \mathrm{ml}$, and Group $1 \mathrm{~N}=6.5 \mathrm{ml}$ ).

On Test Day 1, Group 6E drank the least $(1.1 \mathrm{ml})$, Groups $1 \mathrm{~N}$ and $6 \mathrm{~N}$ drank similar, intermediate amounts of saccharin (2.7 and $2.5 \mathrm{ml}$, respectively), and Group $1 \mathrm{E}$ drank the most $(5.1 \mathrm{ml})$. On Test Day 2, Group 6E continued to avoid the saccharin solution $(7.6 \mathrm{ml})$, whereas the other three groups drank roughly the same amounts
(Group $1 \mathrm{~N}=12.5 \mathrm{ml}$, Group $6 \mathrm{~N}=12.5 \mathrm{ml}$, and Group $1 \mathrm{E}=13.2 \mathrm{ml}$ ). By Test Day 3, all groups appeared to have extinguished the saccharin aversion (Group 6E = $15.9 \mathrm{ml}$, Group $6 \mathrm{~N}=16.5 \mathrm{ml}$, Group $1 \mathrm{E}=17.4 \mathrm{ml}$, and Group $1 \mathrm{E}=17.2 \mathrm{ml}$ ).

Figure 6 depicts the four groups' saccharin consumption averaged over Test Days 1-3. It is apparent that the 1-day groups drank similar amounts, whereas the extinction group at the 6-day interval drank less saccharin than the no-extinction group at that interval. A $2 \times 2 \times 3$ mixed ANOVA was conducted with retention interval (1 day vs. 5 days), extinction (extinction vs. no extinction), and trials (Tests 1,2 , and 3 ) as factors. The ANOVA revealed a significant effect for retention $[F(1,40)=5.22]$ and a nearly significant retention $\times$ extinction interaction $[F(1,40)=$ 3.8, $p=.06]$; however, the extinction effect was not significant $[F(1,40)<1]$. Furthermore, the trials effect $[F(2,80)=351]$ and the extinction $\times$ trials interaction $[F(2,80)=3]$ were significant. However, the retention interval $\times$ trials interaction $[F(2,80)=1.3]$ and the retention interval $\times$ extinction $\times$ trials interaction $[F(2,80)=$ 2.5] were not significant. A simple-effect analysis of the extinction $\times$ trials interaction revealed that a significant extinction effect occurred on Test Day $2[F(1,79)=3.7]$ but not on Test Days $1[F(1,79)<1]$ or $3[F(1,79)<1]$. Since the detection of group differences arising from manipulations of environmental associations was the primary focus of this experiment, data from Test Day 2 were analyzed separately.

Figure 7 displays the mean saccharin intakes of the four groups on Test Day 2. It is obvious that Groups 1E, 1N, and $6 \mathrm{~N}$ drank considerably more on this test than did Group 6E. A $2 \times 2$ ANOVA revealed a significant retention effect $[F(1,40)=3.9]$ and a significant retention $X$ extinction interaction $[F(1,40)=3.8]$. The extinction ef-

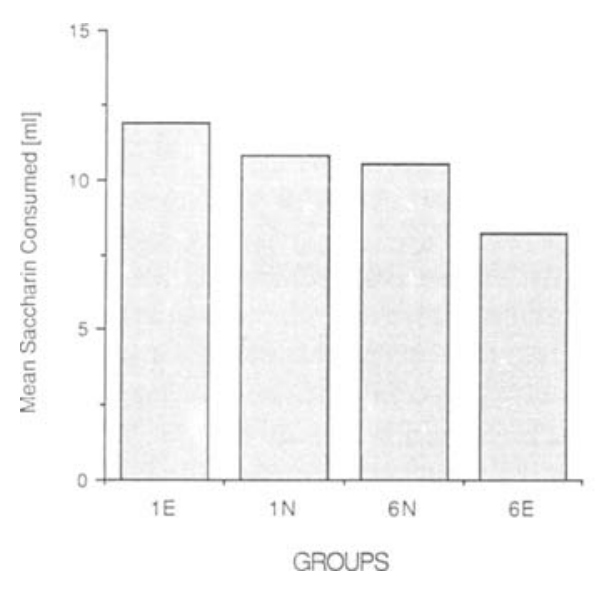

Figure 6. Mean seccharin consumption in millitters of Groups 1E, 1N, 6N, and 6E averaged over Teat Days 1-3. Groups IE and 1N were aversively conditioned to saccharin 1 day before teating, wheress Groups GN and GE were aversively conditioned to soccharth 6 days before testing. Alo, Groups $1 E$ and $6 \mathrm{E}$ spent the cond"tioning to-testing interval in the conditioning environment, wheress Groups $1 \mathrm{~N}$ and $\mathrm{ON}$ were kept in a separate environment during this interval. 


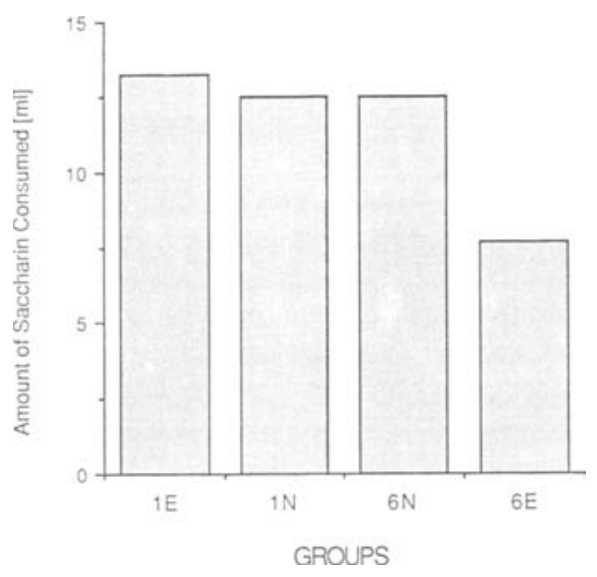

Figure 7. Mean seccharin consumption in milliliters of Groups 1E, 1N, 6N, and 6E presented on Test Day 2. Groups 1E and IN were aversively conditioned to saccharin 1 day before testing, whereas Groups 6N and 6E were aversively conditioned to saccharin 6 days before testing. Also, Groups $1 \mathrm{E}$ and $6 \mathrm{E}$ spent the conditioning-totesting interval in the conditioning environment, whereas Groups $1 \mathrm{~N}$ and $6 \mathrm{~N}$ were kept in a separate environment during this interval.

fect was not significant $[F(1,40)=2.1]$. Planned comparisons revealed that Group $6 \mathrm{E}$ drank significantly less than all of the other groups on this test.

\section{Discussion}

Experiment 6 investigated whether the weakened saccharin aversions observed at a 1-day retention interval were attributable to retrieval interference provided by environmental associations. Groups were conditioned with either a 6- or a 1-day retention interval; next, environmental associations were either extinguished or left intact. The critical comparison for testing the retrievalcompetition explanation involved groups with differential environmental extinction. Specifically, it was predicted that unless it was extinguished, the environment-US association would interfere with the taste-US association and result in a weaker aversion. On Test Day 2, it is clear that Group 6E, which had the most extinction of the home cage environmental cues, had the strongest saccharin aversion. These results are unequivocal: Group $6 \mathrm{E}$ consumed significantly less saccharin than Group $6 \mathrm{~N}$. Thus, these results provide evidence for retrieval competition.

On the other hand, the results of Groups $1 \mathrm{E}$ and $1 \mathrm{~N}$ do not directly support the retrieval-competition hypothesis. As in the case of the 6-day groups, it was predicted that Group 1E would drink less saccharin than would Group 1N; however, the 1-day groups did not drink significantly different amounts of saccharin on any of the tests. In fact, on Test Day 1, Group 1N drank less, albeit not significantly less, than Group 1E. Although this result may be attributable to insufficient time for environmental extinction, an examination of the two no environmental extinction groups may suggest an alternative explanation.
It is noteworthy that the two no environmental extinction groups, Groups $1 \mathrm{~N}$ and $6 \mathrm{~N}$, did not differ but, rather, drank relatively similar amounts during testing. This similarity is important because it demonstrates that the weakened taste aversions at the 1-day interval cannot be solely attributed to time effects. If so, one would expect Group $1 \mathrm{~N}$ to show a weaker aversion than that showed by Group $6 \mathrm{~N}$, regardless of environmental extinction, and this was not the case. Instead, similar factors appear to modulate the performance of these groups. Along with similarities in the absence of environmental extinction, one such factor that may influence the behavior of the noextinction groups, particularly when compared with Group 1E, is differential handling. Prior to testing, these animals were transferred from their breeding cages to their home cages, whereas animals in Groups $6 \mathrm{E}$ and $1 \mathrm{E}$ were not removed and handled. It is possible that the saccharin consumption of the no-extinction groups is partially affected by this movement and handling immediately preceding testing. In fact, this disruption caused by handling may contribute to obscure differences between Groups $6 \mathrm{~N}$ and $6 \mathrm{E}$ on Test Day 1. Furthermore, on Test Day 2, these animals had become more familiar with this procedure and, as a result, their testing intakes were more similar to that of Group $1 \mathrm{E}$ and significantly higher than that of Group 6E.

\section{GENERAL DISCUSSION}

There are several findings of importance in the experiments reported here. For both single-element conditioning and compound conditioning, aversions appeared weaker if tested 1 day after conditioning than if tested 21 days after conditioning. This apparent disruption in the strength of a taste aversion at a 1-day retention interval occurred over multiple test sessions, indicating it was not caused by some transitory influence of the conditioning episode (i.e., illness aftereffects, hydration anomalies, incomplete consolidation of the conditioning experience).

Moreover, combining saccharin and denatonium during conditioning produced overshadowing of denatonium (relative to single-element denatonium controls) and potentiation of saccharin (relative to single-element saccharin controls). Interestingly, however, denatonium overshadowing was more easily detected when tested 1 day after conditioning than when tested 21 days after conditioning. In contrast, saccharin potentiation was stronger at the 21-day retention interval. Although these latter outcomes do not shed light on the reasons why saccharin interferes with denatonium aversions and denatonium enhances saccharin aversions, they do provide some potentially useful perspectives on the processes that determine the performance of ingestional aversions.

As noted earlier, one possible interpretation of the decrement in conditioning to saccharin at a 1-day retention interval in Experiment 1 is a retrieval-competition account. It might be argued that, on a single-taste condi- 
tioning trial, the context, as well as the taste, enters into an association with the lithium. For the associative strength of the taste to be measured accurately, however, it might be further argued that retrieval interference provided by the contextual stimuli must be reduced by extinguishing the association between these environmental stimuli and the lithium US. Because the associative strength of the context should be stronger 1 day after conditioning than after 21 days, it can be predicted that the retrieval interference would be greater at the former interval. Consequently, the taste aversion 1 day after conditioning should appear to be weaker. After a 21-day exposure to the conditioning context, however, the association of these contextual stimuli with lithium should be extinguished, and the retrieval interference on the test should be substantially reduced. The taste aversion, therefore, should appear greater at this longer retention interval.

Although the results of Experiments 1, 2, and 4 could be accommodated by a retrieval-competition interpretation, none of the experiments explicitly manipulated the proposed environment-US associations. As such, Experiment 6 examined the applicability of the retrieval-competition hypothesis by manipulating these associations during the conditioning-to-testing interval. The results of Experiment 6 provide clear evidence that when animals are not exposed to the conditioning environment during the conditioning-to-testing interval, and presumed environmental associations are left intact to interfere with the retrieval of the taste association, weaker taste aversions are observed. These results are consistent with the apparent increase in saccharin aversions noted at a 21-day retention interval relative to those measured 1 day following conditioning.

A similar logic can also be applied to the overshadowing data from Experiment 2. It might be argued that retrieval of the overshadowed element (i.e., denatonium) appears even weaker at a 1 -day retention interval than at a 21-day retention interval because the contextual stimuli provide retrieval interference with the demonstration of the denatonium aversion. At a 21-day retention interval, however, the contextual stimuli have been more thoroughly extinguished and the overshadowed aversion to denatonium therefore appears stronger. It is important to note, though, that denatonium aversions were weaker when this taste had been conditioned in compound with saccharin than when it had been conditioned alone at both the 1-day and the 21-day retention intervals.

The denatonium-mediated potentiation of saccharin aversion at the 21-day retention interval but not at the 1-day retention interval can also be interpreted within the context of a retrieval-interference framework. In the absence of extinction encounters with the conditioning context, these stimuli would be expected to provide retrieval interference with the potentiated taste (i.e., saccharin). Consequently, the measured aversiveness of this taste should be lower at a 1-day retention interval than at a 21day retention interval. Again, the relative aversiveness of saccharin in the DEN and DEN + SAC groups should not change with changes in the interval. Consistent with this, although significant saccharin potentiation was observed only at the 21-day retention interval, similar effects on the 1-day tests might have been obscured by the greater retrieval interference at this interval.

Inherent in the retrieval-interference interpretation of the differential retention functions for overshadowing and potentiation is the assumption that two tastes, or a taste and an odor, interact in compound during conditioning in ways that produce decrements to one of the elements and increments to the other. Unfortunately, the mechanisms underlying these asymmetrical effects are poorly understood. Presently, indications are that the more associable (i.e., the more "salient") of the two stimuli will be overshadowed, whereas the less associable stimulus will be potentiated (Bouton, Dunlap, \& Swartzentruber, 1987; Bouton, Jones, McPhillips, \& Swartzentruber, 1986). A more thorough understanding of the basic processes of these phenomena, however, will be necessary before the role of retrieval interference in overshadowing and potentiation can be accurately specified.

The retrieval-interference interpretation offered here is anticipated by various related accounts of animal conditioning and memory. R. R. Miller and his colleagues (e.g., Kasprow et al., 1987; Matzel, Schachtman, \& Miller, 1985; Matzel, Shuster, \& Miller, 1987; R. R. Miller \& Schachtman, 1985; Schachtman, Brown, Gordon, Catterson, \& Miller, 1987) have proposed a "comparator model" to incorporate a diverse set of behavioral phenomena. One assumption of this conceptual framework is that the behavioral response to any conditioned stimulus is largely determined by the relative associative strengths of the target stimulus and all other elements. Larger associative differences between the target and other stimuli produce greater responding to the target. Within the present context, the excitatory reaction to a target stimulus should be greater after the extinction of comparator contextual stimuli than in the absence of such postconditioning exposure to these stimuli. This comparator account is in agreement with the single-taste outcomes of Experiments 1, 2, 4, and 6, as well as with the overshadowing results of Experiment 2 and the potentiation results of Experiment 4.

In contrast, the retrieval-interference interpretation offers no mechanism for the reactivation of an association that is obscured by other processes (see Gordon, Smith, \& Katz, 1979; Kasprow, Cacheiro, Balaz, \& Miller, 1982; Spear, 1978). In fact, the assumption of the retrieval-competition hypothesis is that stronger responding to a target-conditioned stimulus results not from a reactivation of existing associations but, instead, from a relative absence of competing stimuli with prior associations with the unconditioned stimulus. In this regard, it is in greater accord with the comparator account offered by $\mathbf{R}$. R. Miller and his colleagues.

The precise role exerted by contextual cues in the production of retrieval competition is presently unclear. The interpretation receiving the most emphasis in Experi- 
ments 1-6 is an associative account. However, the results of these experiments invite additional speculation. One possible problem with an associative analysis of these data is that associations between the context and toxicosis or between the context and the taste might be expected to produce associative summation when the taste is tested in the presence of these environmental stimuli. This should create the appearance of even greater aversion to the taste than would be observed in the absence of environmental conditioning. Such associative summation might be expected to produce outcomes opposite to those mediated by retrieval competition. However, if the contextual stimuli are dishabituated by, rather than associated with, the US during conditioning, the environmental stimuli might disrupt retrieval of the taste aversion during the test. Because novel environmental stimuli should be more likely to be associated with the US, familiar contextual cues should be more likely to generate retrieval interference. Indeed, taste conditioning occurred in Experiments 1-6 in the presence of highly familiar contextual stimuli. One distinctive aspect of this dishabituation position is that not only should post-US exposure to the context rehabituate these stimuli, increases in the US-to-testing interval might also be expected to dissipate the potential of the environmental stimuli to exert retrieval competition. An associative analysis, on the other hand, places exclusive emphasis on extinction of the contextual cues for the diminution of retrieval competition.

From a practical standpoint, the results of these experiments point to the importance of multiple tests in the assessment of conditioned taste aversions, particularly following compound conditioning. In the reports of Kraemer et al. (1988) and J. S. Miller et al. (1990, Experiment 1), only one test was conducted, and significant overshadowing was observed exclusively at the 1-day retention interval. In Experiment 2, overshadowing was observed at both the 1-day and the 21-day retention intervals when multiple tests were conducted. It is clear from the current results that a single test might not be sufficient to reveal strong and reliable multiple-stimulus interactions. Taken together, therefore, the results of these experiments demonstrate the importance of conducting more than one of the interactions of compound stimuli, as well as the effects of conditioning, on a single-flavor stimulus following conditioning.

Finally, it is clear from these results that taste-aversion learning is most accurately assessed, both for single- and compound-element procedures, when tests are delayed at least several days after conditioning. The results, especially of Experiment 6, also imply that, if tests for taste aversions occur in the presence of contextual stimuli that occurred during conditioning, these stimuli should also be present during the conditioning-to-testing interval. Such access will afford sufficient opportunity to extinguish any association between these contextual stimuli and toxicosis that might constitute competition to the measurement of the flavor aversion. The utilization of these types of conditioning and testing techniques should make for a more precise assessment of single-element taste aversions, but also for a more precise measurement of overshadowing and potentiation. This, in turn, should allow for a better evaluation of the associative, memorial, and performance mechanisms of these compound-conditioning phenomena.

\section{REFERENCES}

Batsell, W. R., JR., \& Best, M. R. (1990, November). Differential taste aversions resulting from varying retention intervals. Poster presented at the 31st Annual Meeting of the Psychonomic Society, New Orleans.

BAtson, J. D., \& Best, M. R. (1982). Lithium-mediated disruptions of latent inhibition: Overshadowing by the unconditioned stimulus in flavor conditioning. Leaming \& Motivation, 13, 167-184.

BATson, J. D., \& Best, P. J. (1979). Drug-preexposure effects in flavoraversion learning: Associative interference by conditioned environmental stimuli. Joumal of Experimental Psychology: Animal Behavior Processes, 5, 273-283.

Best, M. R., Batson, J. D., Meachum, C. L., Brown, E. R., * RINGER, M. (1985). Characteristics of taste-mediated environmental potentiation in rats. Learning \& Motivation, 16, 190-209.

BeST, M. R., Brown, E. R., \& Sowell, M. K. (1984). Taste-mediated potentiation of noningestional stimuli in rats. Leaming \& Motivation, 15, 244-258.

Best, M. R., Domun, M. (1979). Characteristics of the lithiummediated proximal US-preexposure effect in flavor-aversion conditioning. Animal Learning \& Behavior, 7, 433-440.

Best, M. R., \& MEACHUM, C. L. (1986). The effects of stimulus preexposure on taste-mediated environmental conditioning: Potentiation and overshadowing. Animal Learning \& Behavior, 14, 1-5.

Best, P. f., Best, M. R., Henggeler, S. (1977). The contribution of environmental noningestive cues in conditioning with aversive internal consequences. In L. M. Barker, M. R. Best, \& M. Domjan (Eds.), Leaming mechanisms in food selection (pp. 371-394). Waco, TX: Baylor University Press.

Biederman, G. B., Milgram, N. W., Heighington, G. A., StockMaN, S. M., O'NeILl, W. (1974). Memory of conditioned food aversion follows a U-shape function in rats. Quarterly Journal of Experimental Psychology, 26, 610-615.

Bonardi, C., Honey, R. C., Hall, G. (1990). Context specificity of conditioning in flavor-aversion learning: Extinction and blocking tests. Animal Learning \& Behavior, 18, 229-237.

BoND, N., HARLAND, W. (1975). Effect of amount of solution drunk on taste-aversion learning. Bulletin of the Psychonomic Society, $\mathbf{5}$, 219-220.

Bouton, M. E., Dunlap, C. M., \& Swartzentruber, D. (1987). Potentiation of taste by another taste during compound aversion learning. Animal Learning \& Behavior, 15, 433-438.

Bouton, M. E., Jones, D. L., McPhillips, S. A., \& SwArtzenTRUBER, D. (1986). Potentiation and overshadowing in odor-aversion learning: Role of method of odor presentation, the distal-proximal cue distinction, and the conditionability of odor. Learning \& Motivation, 17, 115-138.

Brookshire, K. H., \& BrACKBILL, R. M. (1976). Formation and retention of conditioned taste aversions and UCS habituation. Bulletin of the Psychonomic Society, 7, 125-128.

Colby, J. J., \& SMIT, N. F. (1977). The effect of three procedures for eliminating a conditioned taste aversion in the rat. Learning \& Motivation, 8, 404-413.

DAvis, S. F., Best, M. R., Grover, C. A. (1988). Toxicosis-mediated potentiation in a taste/taste compound: Evidence for within-compound associations. Leaming \& Motivation, 19, 183-205.

Davis, S. F., Best, M. R., Grover, C. A., Bailey, S. A., Freeman, B. L., MAYleben, M. A. (1990). The effects of taste extinction on ingestional potentiation in weanfing rats. Animal Learning \& Behavior, 18, 444-452.

Domjan, M. (1977). Attenuation and enhancement of neophobia for edible substances. In L. M. Barker, M. R. Best, \& M. Domjan (Eds.), 
Learning mechanisms in food selection (pp. 151-180). Waco, TX: Baylor University Press.

Domjan, M., \& Best, M. R. (1977). Paradoxical effects of proximal unconditioned stimulus preexposure: Interference with and conditioning of a taste aversion. Journal of Experimental Psychology: Animal Behavior Processes, 3, 310-321.

Eluns, S. R., Cramer, R. E., Whitmore, C. (1985). Taste potentiation of auditory aversions in rats (Rattus norvegicus): A case for spatial contiguity. Journal of Comparative Psychology, 99, 108-111.

GALEF, B. G., JR., \& OsBorNe, B. (1978). Novel taste facilitation of the association of visual cues with toxicosis in rats. Journal of Comparative \& Physiological Psychology, 92, 907-916.

Gordon, W. C., Smith, G. J., \& KatZ, D. S. (1979). Dual effects of response blocking following avoidance learning. Behavior Research \& Therapy, 17, 479-489.

Holman, E. W. (1976). The effect of drug habituation before and after taste aversion learning in rats. Animal Leaming \& Behavior, 4, 329-332.

Kasprow, W. J., Cacheiro, H., Balaz, M. A., * Miller, R. R. (1982). Recovery of associations to an overshadowed stimulus. Learning \& Motivation, 13, 155-166.

Kasprow, W. J., Schachtman, T. R., Miller, R. R. (1987). The comparator hypothesis of conditioned response generation: Manifest conditioned excitation and inhibition as a function of relative excitatory strengths of CS and conditioning context at the time of testing. Joumal of Experimental Psychology: Animal Behavior Processes, 13, $395-406$.

Kaufman, M. A., Bolles, R. C. (1981). A nonassociative aspect of overshadowing. Bulletin of the Psychonomic Society, 18, 318-320.

Kraemer, P. J., Lariviere, N. A., \& Spear, N. E. (1988). Expression of a taste aversion conditioned with an odor-taste compound: Overshadowing is relatively weak in weanlings and decreases over a retention interval in adults. Animal Learning \& Behavior, 16, 164-168.

LoLordo, V. M., \& Droungas, A. (1989). Selective associations and adaptive specializations: Taste aversions and phobias. In S. B. Klein \& R. R. Mowrer (Eds.), Contemporary leaming theories: Instnumental conditioning theory and the impact of biological constraints on leaming (pp. 145-180). Hillsdale, NJ: Erlbaum.

Matzel, L. D., Schachtman, T. R., Miller, R. R. (1985). Recovery of an overshadowed association achieved by extinction of the overshadowing stimulus. Leaming \& Motivation, 16, 398-412.

Matzel, L. D., Shuster, K., Miller, R. R. (1987). Covariation in conditioned response strength between stimuli trained in compound. Animal Leaming \& Behavior, 15, 439-447.

Mikulka, P. J., LeArd, B., K Klein, S. B. (1977). Illness-alone exposure as a source of interference with the acquisition and retention of a taste aversion. Joumal of Experimental Psychology: Animal Behavior Processes, 3, 189-201.

Miller, J. S., Jagielo, J. A., \&PeAr, N. E. (1990). Changes in the retrievability of associations to elements of the compound CS determine the expression of overshadowing. Animal Learning \& Behavior, 18, 157-161.

Miller, J. S., McCoy, D. F., Kelly, K. S., BArdo, M. T. (1986). A within-event analysis of taste-potentiated odor and contextual aversions. Animal Learning \& Behavior, 14, 15-21.
Miller, R. R., \& Schachtman, T. R. (1985). Conditioning context as an associative baseline: Implications for response generation and conditioned inhibition. In R. R. Miller \& N. E. Spear (Eds.), Information processing in animals: Conditioned inhibition (pp. 51-88). Hillsdale, NJ: Erlbaum.

Mitchell, D., Kirschbaum, E. H., \& Perry, R. L. (1975). Effects of neophobia and habituation on the poison-induced avoidance of exteroceptive stimuli in the rat. Joumal of Experimental Psychology: Animal Behavior Processes, 104, 47-55.

NaChMaN, M., Ashe, J. H. (1973). Leamed taste aversions in rats as a function of dosage, concentration, and route of administration of $\mathrm{LiCl}$. Physiology \& Behavior, 10, 73-78.

Riley, A. L., Jacobs, W. J., \& Lolondo, V. M. (1976). Drug exposure and the acquisition and retention of a taste aversion. Joumal of Comparative \& Physiological Psychology, 90, 799-807.

Rudy, J. W., Rosenberg, L., \& Sandell, J. H. (1977). Disnuption of a taste familiarity effect by novel exteroceptive stimulation. Journal of Experimental Psychology: Animal Behavior Processes, 3, 26-36.

Rusiniak, K. W., Hankins, W. G., Garcla, J., \& BretT, L. P. (1979). Flavor-illness aversions: Potentiation of odor by taste in rats. Behavioral \& Neural Biology, 25, 1-17.

Schachtman, T. R., Brown, A. M., Gordon, E., Catterson, D., * Miller, R. R. (1987). Mechanisms underlying retarded emergence of conditioned responding following inhibitory training: Evidence for the comparator hypothesis. Joumal of Experimental Psychology: Animal Behavior Processes, 13, 310-322.

SPEAR, N. E. (1978). The processing of memories: Forgetting and retention. Hillsdale, NJ: Erlbaum.

Westbrook, R. F., \& Brookes, N. (1988). Potentiation and blocking of conditioned flavour and context aversions. Quarterly Journal of Experimental Psychology, 40B, 3-30.

\section{NOTE}

1. A $2 \times 2$ ANOVA with retention interval ( 1 day vs. 21 days) and liquid factors (denatonium vs. saccharin + denatonium) was used to analyze the conditioning intakes. Significant retention interval $[F(1,36)=$ 4.9] and liquid effects $[F(1,36)=4.1]$ were detected, but the interaction effect was not significant $[F(1,36)<1]$. Although significant group differences were observed during conditioning, this result was not believed to be the determining factor in the differences obtained during testing. Bond and Harland (1975) demonstrated that relatively small intakes (i.e., $2 \mathrm{ml}$ ) during conditioning produce weaker aversions than moderate CS amounts (i.e., $5 \mathrm{ml}$ ). However, in Experiment 2, Group R21-DEN, which drank the least during conditioning (1.91 ml), possessed the strongest denatonium aversion. Obviously, any deficits caused by the decreased consumption during conditioning were easily overridden by the other experimental procedures.

(Manuscript received June 7, 1991; revision accepted for publication November 10, 1991.) 